Dr PHILIP CASS is reviews editor of Pacific Journalism Review.

\section{More than just a naughty boy}

Kim Dotcom:Caught in the Web, directed by Annie Goldson. Produced by Alexander Behse. Monsoon Pictures. Documentary. 2017. $107 \mathrm{~min}$.

$T$ HE QUESTION about Kim Dotcom that nobody seems able to resolve is whether he's just been a bit naughty and the authorities are over-reacting, or whether he has in fact been very bad.

Early in his sojourn in New Zealand, Kim Dotcom perfected the image of a great big German huggy bear with a beautiful wife, who was being persecuted simply for giving people a better internet file sharing system.

The fact that the government appeared to be kowtowing to the demands of the FBI so soon after it grovelled to Warner Brothers over the Hobbit films made it easy for New Zealanders' knee-jerk anti-Americanism to kick in and obscure some of the questions that needed to be answered.

Even a cursory search of the internet shows that in different incarnations he has been involved in some very questionable activities.

Annie Goldson's documentary goes a long way to exposing just how badly the New Zealand government acted in its dawn raid on Dotcom's mansion and its acquiescence to the FBI's demands.

It also provides evidence that allowing Dotcom to settle in New Zealand may

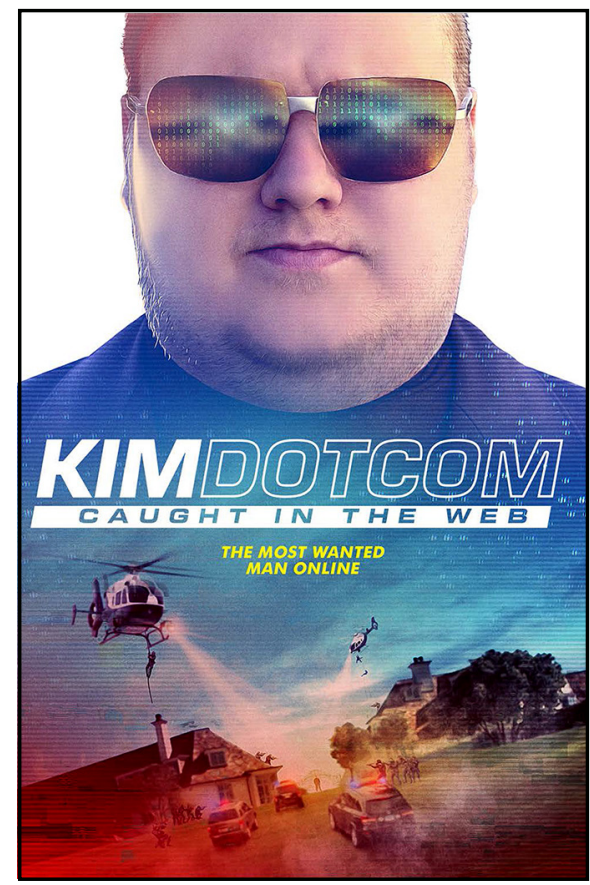

well have been a trap to place him in a country where a compliant government would arrange for him to be deported and punished as an 'internet pirate'.

However, in interviews with Dotcom and by using footage from his private video collection, the film also shows a deeply lonely man; a genius who needs to surround himself with famous and glamorous people.

When the film ends, Dotcom's legal troubles are not over; his venture into politics has ended in ignominy and his wife has left him.

The film leaves audiences with a clear impression that Dotcom has been more than just a naughty boy. However, the behaviour of the New Zealand government as depicted in the film will probably mean that people will maintain their sympathy for him, no matter what he has done. 